\title{
Fatigue Strength Assessment of Semi-Submersible Floating Wind Turbine Foundation under Turbulent Wind
}

\author{
SANG Song ${ }^{1, *}$, CHU Zhaofei ${ }^{1}$, CAO Aixia ${ }^{2}$, DONG Zixin ${ }^{1}$, DONG Jinqi ${ }^{1}$ \\ 1.School of Engineering, Ocean University of China, Qingdao 266100,China; \\ 2. College of Traffic and Ship Engineering, Qingdao Huanghai University, Qingdao \\ 266427, China
}

\begin{abstract}
Under the complex marine environment load and the role of the upper wind turbine load, deep sea floating wind turbine support structure would suffer fatigue damage, which often endangers the safety of the wind turbine system. This paper chose the "5 MW baseline" wind turbine model which published by the US National Renewable Energy Laboratory (NREL) as the design basis. The paper uses the OC4-DeepC wind semi-submersible offshore wind turbine model for the verification of offshore floating wind turbines. According to the characteristics of stress and the distribution of stress, the paper selects seven key parts which are prone to fatigue damage are screened, respectively established local finite element models and carried out grid encryption. Based on the SESAM hydrodynamic analysis software and FAST wind motor dynamic load calculation procedure, the fatigue damage of the target node under the action of wind turbine load is studied. The results show that the structural fatigue damage occurs mainly at the horizontal connection of the upper part of the neutral column and the diagonal connection of the lower part of the neutral column. The fatigue damage degree of the crown and the saddle point is relatively large at the connecting rod position.
\end{abstract}

Key words: floating wind turbine foundation; fatigue hot spot; influence coefficient; FAST software; fatigue damage degree

\section{Introduction}

Wind power is the most important form of wind energy utilization, with mature technology, which is increasingly occupying the core position in the national new energy development strategy. As an important part of the floating wind power system, the key technologies of the floating support structure are directly related to the social economy of the floating wind farm and whether it can be widely promoted. Deep sea floating wind turbine support structure in the complex marine environmental load and the upper wind turbine load under the action, is prone to fatigue damage, which often endangers the safety of the wind turbine system, and reduces the life of the support structure. Offshore wind power system is different from the offshore oil platform structural design on the fatigue analysis under the wind load [1]. The traditional oil recovery platform is mainly subjected to the fatigue cycle load caused by the waves. The wind load is usually negligible. In addition to the cyclic load of the wave, the aerodynamic load generated by the wind load and the rotation of the wind turbine blades [2] is also the main load of the system. From the experience of the existing offshore wind farms in Europe, it can be seen that the fatigue load produced by the wind turbine operation is the main basis for the fatigue design of the foundation under the relatively moderate marine environment. Offshore wind turbine design specifications such as IEC 61400-3 [3], GL offshore wind turbine certification [4] and so on have detailed requirements on the fatigue load environment. These regulations describe the design load conditions under the wind speed and sea conditions, the normal operating conditions of the wind turbine, and other special conditions in the wind speed coherence distribution.

Jonkman [5] uses the fully coupled numerical simulation tool to analyze the design conditions of the floating bucket at sea. Jonkman refers to the normal power generation, fault power generation, shutdown and fault shutdown in the specification.Jonkman defines the wind load model.The wind load model includes extremely coherent gust of direction (ECD), extreme wind gust (ESS), extreme wind turbulence model (ETM), extreme wind speed shear (EWS), normal sea conditions (NSS), normal turbulence model (NTM), etc .P.Schaumann et al. [6] proposed that the wind turbine structure would withstand about 109 cycles of load within the estimated 20 years of service life. They concluded that for offshore wind turbines, weld joints and grout joints are prone to fatigue and are very special parts; Sergio Márquez-Domínguez and other scholars from University of Aalborg[7] conducted in-depth study on the offshore wind turbine steel structure fatigue design Factor DFF (Design Fatigue Factor). It is found that the fatigue effect of ocean wind turbine is smaller than that of oil and gas platform under

\footnotetext{
* Corresponding author: Sangsong, E-mail: sangqi @ouc.edu.cn, 13573830323
} 
normal circumstances. Therefore, the fatigue analysis factor of offshore wind power foundation can adopt smaller fatigue design factor. Most of the work focuses on the fatigue damage study of the wind turbine mechanism under the wave load. However, there are few studies on the fatigue damage of the structural foundation under the action of turbulent wind load need to be further studied.

\section{Critical screening of fatigue and local model establishment \\ 2.1. Critical parts of fatigue screening}

From the analysis of the overall strength of the structure, it can be seen that the hot spots which are prone to fatigue under the combined action of wind and waves are generally the intersection of the structure pilfer and the column, the column and the brace. These parts, due to the discontinuity of the structure, led to the stress concentration phenomenon. Under the action of alternating cyclic load, they are prone to fatigue damage. In this paper, seven representative key parts are selected to study the structural damage. The position is shown in Fig.1.

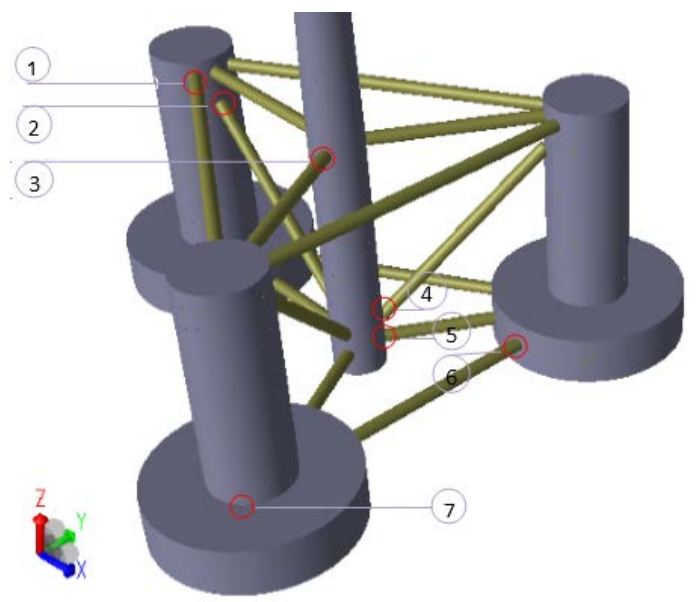

Fig. 1 Schematic diagram of the key points of fatigue analysis

In the Fig.1, positions 1 and 2 are the welding of the brace and the upper part of the column. The position 3 is the welding of the upper part of the brace and the neutral column. Position 4 and 5 are the brackets and the brackets.Position 6 is the weld of the cross brace and the lower buoy. Position 7 is the side of the column and the float connected to the welding site. These key positions basically contain the parts that are more prone to dangerous structurally.

\subsection{Local model establishment}

The finite element model of the typical node is established by the plate element. Since the result of the typical node model is used for the fatigue analysis, the quadrilateral plate element is used near the column and the pole connection, and the unit scale is about $\mathrm{t} \times \mathrm{t}$ ( $\mathrm{T}$ is the thickness), Fig 2 (a-e) for the key local model.

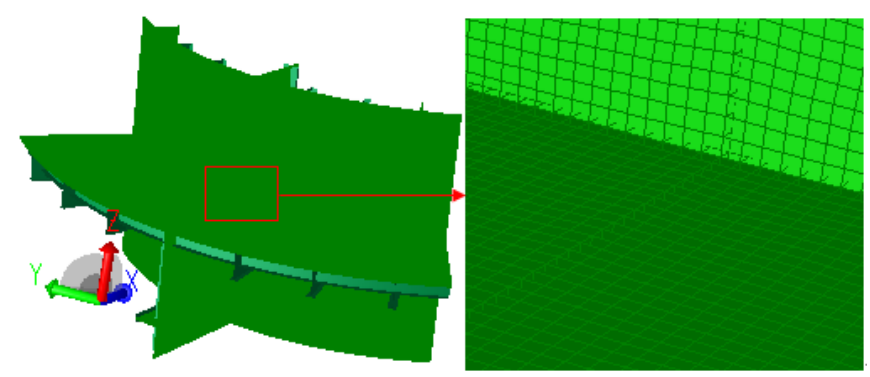

(a) the finite element model of the typical node at the connection between the side and side pontoon 


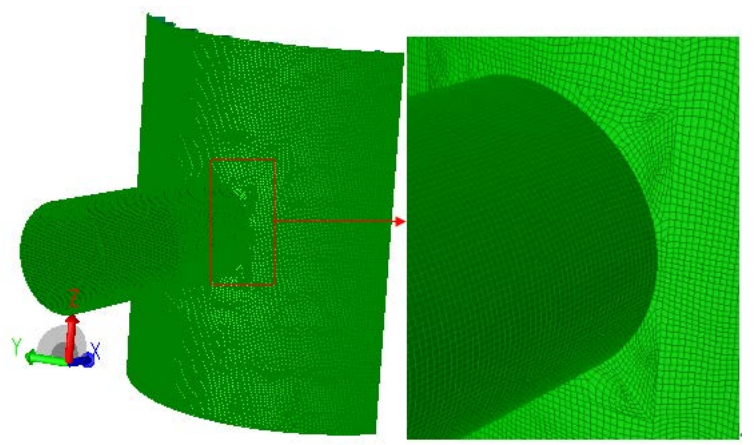

(b) The finite element model of the typical node of the middle column and the pole connection (above the waterline)

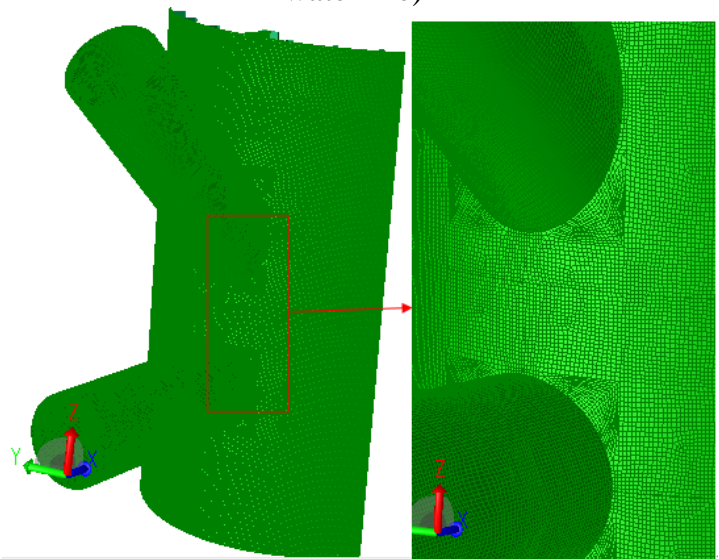

(c) the finite element model of the typical node and the connecting rod (below the waterline)

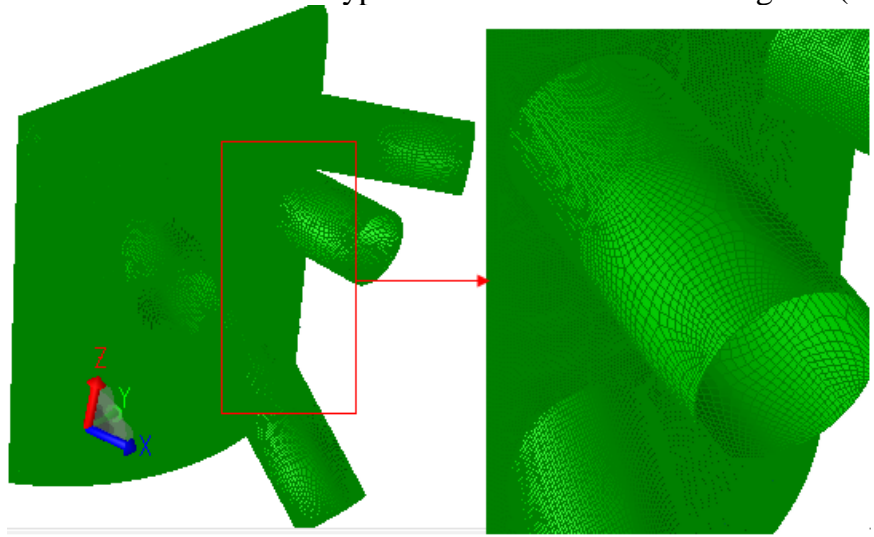

(d) the finite element model for typical joints of lateral column and pole connection

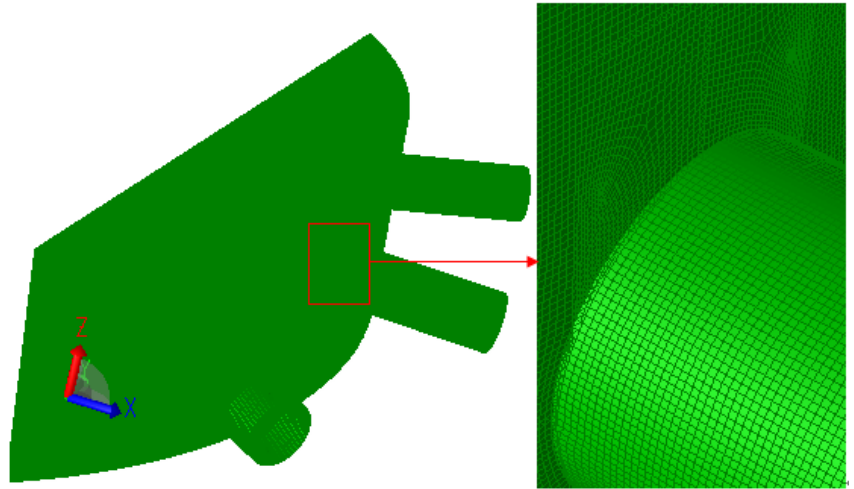

(e) the finite element model for yypical joints of side pontoon and pole connection Fig. 2 Typical node local model 
[DNV-RP-C203, 2010] The Design Fatigue Factor (DFF) is used as the safety factor of the fatigue strength design. After calculating the fatigue damage multiplied by the fatigue safety factor, the specification should be met DFF $=3$ in this article.

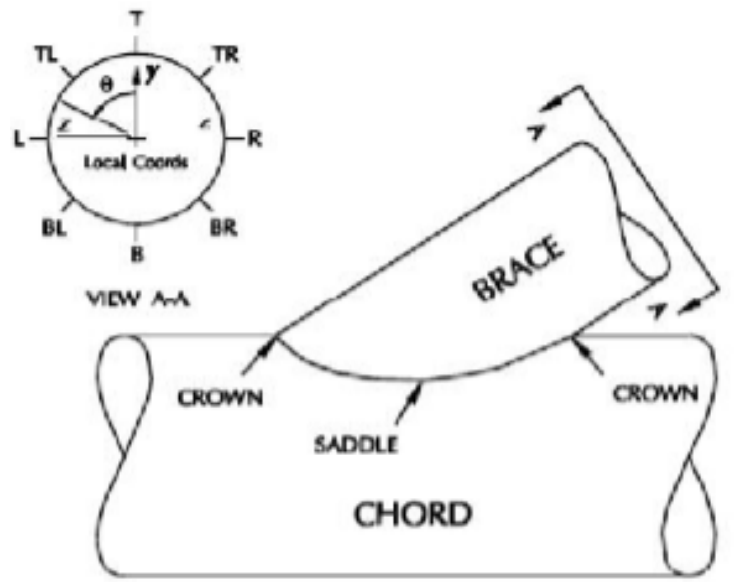

Fig.3 Selection of fatigue hot spots

T, TR, B, BL, L, TL, T, T for the top, B on behalf of the bottom, L on behalf of left, R on behalf of the end of the line, right. The key part is the structural welding site. In the fatigue analysis, the stress at the tip of the weld is obtained by extrapolation as the nominal hot stress, as shown in Fig.3

\section{Fatigue calculation under wind turbine load}

\subsection{Fatigue analysis conditions}

At present, since floating floating wind turbine is still in the research stage and has not yet entered the commercial development process, the paper can only borrow from the sea fixed wind turbine and offshore floating platform of the relevant norms. According to the International Electro Technical Organization on the offshore wind turbine standard IEC61400-3, the wind turbine load fatigue is calculated. DLC1.2, DLC1.4, DLC1.1, DLC4.1, DLC6.4, DLC7.2, DLC8.3 are fatigue load conditions. DLC1.2 is the normal power generation fatigue analysis conditions. The calculation process requests the consideration of atmospheric turbulence, (NSS) should be used. On the basis of the long-term joint probability distribution of the marine meteorological parameters, the paper select the intended site, the mean wave height, peak period and direction, and the average wind speed corresponding to each normal sea condition. It should be ensured that the number and resolution of the normal sea conditions under consideration adequately address the fatigue damage associated with the long-term distribution of marine meteorological parameters. For the design load case DLC1.2, each average wind speed can be considered for a corresponding significant wave of high value. Based on the long-term joint probability distribution of marine meteorological data, the normal wave height, peak period, wave direction and water level of the normal sea conditions corresponding to the average wind speed should be determined.Usually the average wind speed resolution should not be greater than $2 \mathrm{~m} / \mathrm{s}$. Due to the lack of the corresponding wind turbine control parameters,and the wind turbine in the life of the vast majority of the time is the normal power generation state, the fatigue load calculation only considers the normal power generation conditions. According to the wind speed of $3 \mathrm{~m} / \mathrm{s}$ wind speed and the cutting speed of $25 \mathrm{~m} / \mathrm{s}$, the wind speed of the hub is $4 \mathrm{~m} / \mathrm{s}, 6 \mathrm{~m} / \mathrm{s}, 8 \mathrm{~m} / \mathrm{s}, 10 \mathrm{~m} / \mathrm{s}, 12 \mathrm{~m} / \mathrm{s}, 14 \mathrm{~m} / \mathrm{s}, 16 \mathrm{~m} / \mathrm{s}, 18 \mathrm{~m} / \mathrm{s}, 20 \mathrm{~m} / \mathrm{s}, 22 \mathrm{~m} / \mathrm{s}, 24 \mathrm{~m}$ / s total 11 wind speed calculation is selected and calculated in this paper. According to the variation coefficient of wind pressure, the wind speed range of the corresponding sea level $10 \mathrm{~m}$ is $2 \mathrm{~m} / \mathrm{s} \sim 18 \mathrm{~m} / \mathrm{s}$. The calculated operating conditions and the direction probability are shown in Table 1, and the total occurrence probability is 85.04\%.

Fatigue calculations should take into account each possible average wind speed, effective wave height, peak period and possible direction combination and probability distribution, which means that a large number of time-domain simulations should be made for all short-term sea conditions. Due to time constraints and lack of corresponding storms, in this paper, the wind width of the region is calculated according to the following formula to calculate the mean wave height and the peak period [8].

The average wind speed is assumed to be subject to the Weibull distribution.The wind speed is expressed by $\mathrm{w}$, then the corresponding wave height and period can be expressed as a function related to wind speed:

$$
E\left(H_{s}\right)=h=\beta_{h} \Gamma\left(\frac{1}{\alpha_{h}}+1\right)
$$


Therein $\alpha_{h}=2.0+0.135 w, \beta_{h}=1.8+0.100 w^{1322}$,

$$
E\left(T_{p}\right)=\bar{T}_{p}(w, h)=\left(4.883+2.68 h^{0.529}\right) \cdot\left[1-0.19 \cdot\left(\frac{w-\left(1.764+3.426 h^{0.78}\right)}{1.764+3.426 h^{0.78}}\right)^{1}\right]
$$

Turbulence intensity factor

$$
T_{I}=\frac{\sigma_{I}}{w}
$$

The standard deviation of the turbulence

$$
\sigma_{I}=I_{\text {ref }}(0.75 \mathrm{w}+b) ; b=5.6 \mathrm{~m} / \mathrm{s}
$$

is the average wind speed of $15 \mathrm{~m} / \mathrm{s}$ corresponding to the turbulence intensity value, take 0.12 (Class C, [IEC61400-3, 2005]), wind and wave joint probability distribution as shown in Table 1.

Table 1 Joint probability distribution of wind and wave

\begin{tabular}{cccccc}
\hline$W_{\text {hub }}$ & $\boldsymbol{W}_{10}$ & $\begin{array}{c}\text { Significant } \\
\text { wave } \\
\text { height }\end{array}$ & $\begin{array}{c}\text { Tp Peak } \\
\text { period }\end{array}$ & $\begin{array}{c}\text { Occurrence } \\
\text { probability }\end{array}$ & $\begin{array}{c}\text { Turbulence } \\
\text { intensity TI }\end{array}$ \\
\hline 4 & 2.94 & 1.96 & 9.73 & 22.83 & 0.258 \\
6 & 4.41 & 2.23 & 9.76 & 14.165 & 0.202 \\
8 & 5.88 & 2.53 & 9.85 & 14.165 & 0.174 \\
10 & 7.35 & 2.86 & 9.97 & 14.44 & 0.157 \\
12 & 8.82 & 3.20 & 10.11 & 13.68 & 0.146 \\
14 & 10.29 & 3.58 & 10.27 & 1.42 & 0.138 \\
16 & 11.76 & 3.97 & 10.44 & 1.42 & 0.132 \\
18 & 13.24 & 4.37 & 10.63 & 1.83 & 0.127 \\
20 & 14.71 & 4.80 & 10.82 & 0.6 & 0.124 \\
22 & 16.18 & 5.24 & 11.02 & 0.245 & 0.121 \\
24 & 17.65 & 5.69 & 11.23 & 0.245 & 0.118 \\
\hline
\end{tabular}

\subsection{Calculation of Time - Dependent Force of Bottom wind turbine Load}

The airfoil parameters and tower parameters and control system parameters of the NREL5MW three-blade wind turbine, wind turbine blades used in this paper are provided by NREL. The hydrodynamic parameters such as mass, additional mass, damping, response force matrix and first-order wave force transfer function of the wind turbine foundation are calculated by SESAM-HydroD and imported into the FAST-HydroDyn module to calculate the dynamic response of the wind turbine foundation. AeroDyn's turbulent wind fields are generated by Turbsim.

The turbulence wind load is generated by Turbsim. The Kaimal spectrum is obtained from the wind speed spectrum. The characteristic of the turbulence intensity is 0.12 .The wind speed corresponding to the wheel is $4 \mathrm{~m} / \mathrm{s}, 6 \mathrm{~m} / \mathrm{s}, 8 \mathrm{~m} / \mathrm{s}, 10 \mathrm{~m} / \mathrm{s}, 12 \mathrm{~m} / \mathrm{s}, 14 \mathrm{~m} / \mathrm{s}, 16 \mathrm{~m} / \mathrm{s}, 18 \mathrm{~m} / \mathrm{s}, 20 \mathrm{~m} / \mathrm{s}, 22 \mathrm{~m} / \mathrm{s}, 24 \mathrm{~m} / \mathrm{s}$ wind speed time course.Fig. 4 is for four wind speed time curve.
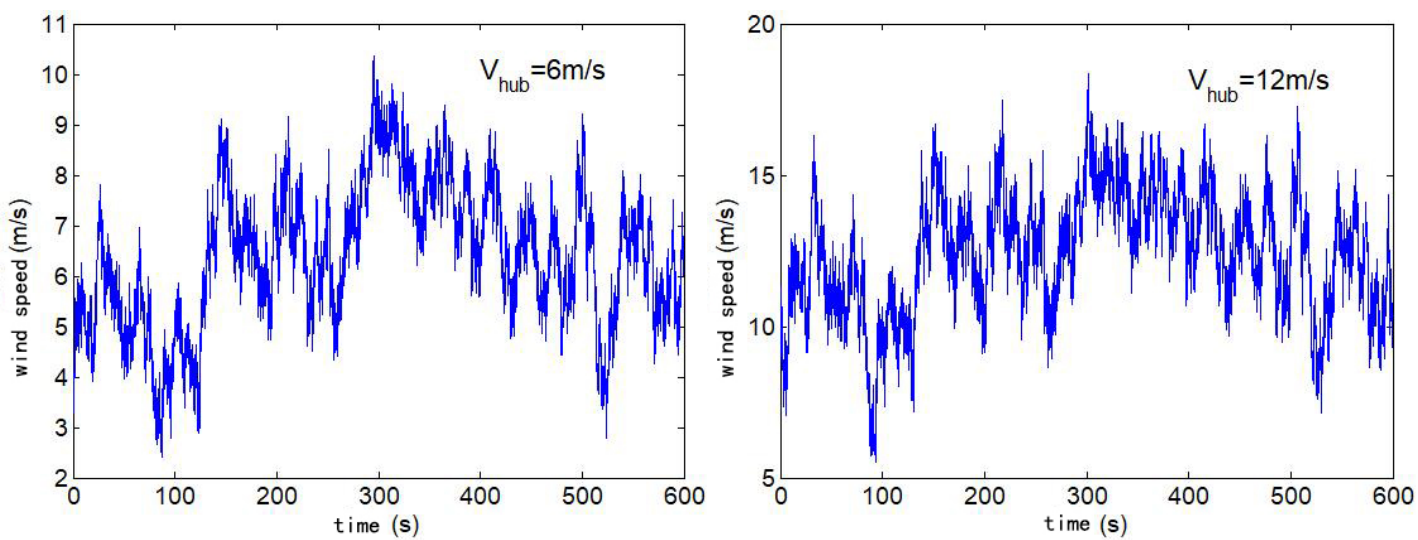

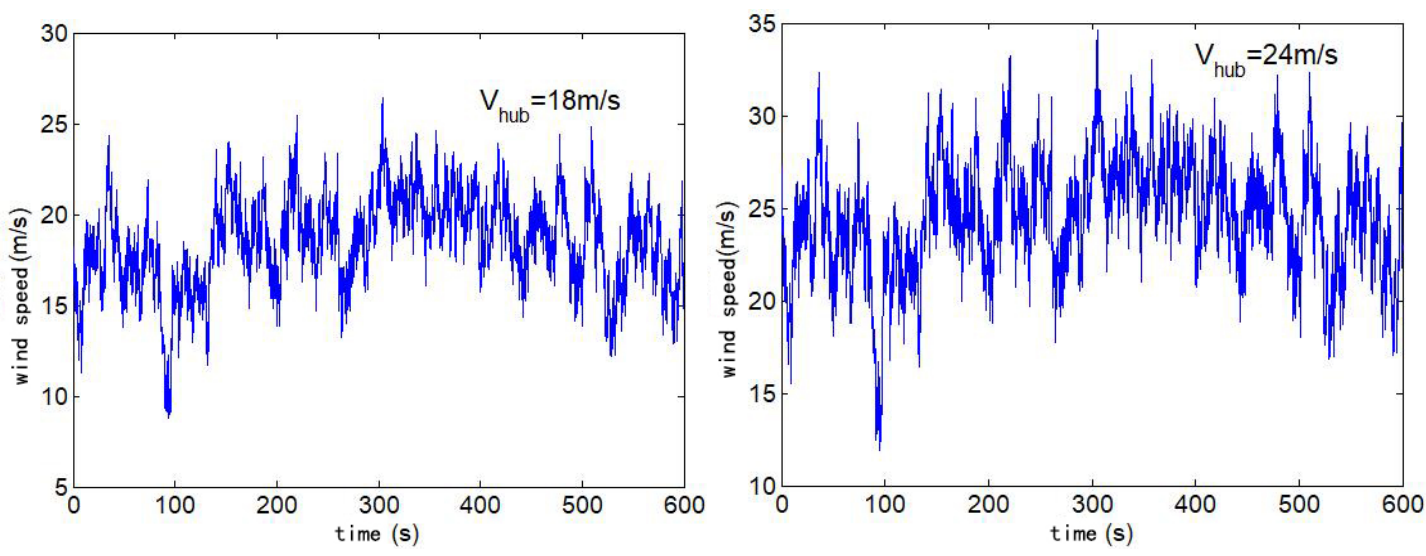

Fig. 4 Turbsim turbulence wind speed time curve

The wind speed is introduced into the Fast software, and the wind turbine load of six degrees of freedom at the bottom of the tower is generated by Fast. The average wind speed is $6 \mathrm{~m} / \mathrm{s}, 12 \mathrm{~m} / \mathrm{s}, 18 \mathrm{~m} / \mathrm{s}, 24 \mathrm{~m} / \mathrm{s}$ wind direction of $0^{\circ}$ when the tower at the bottom of the wind turbine load six components.
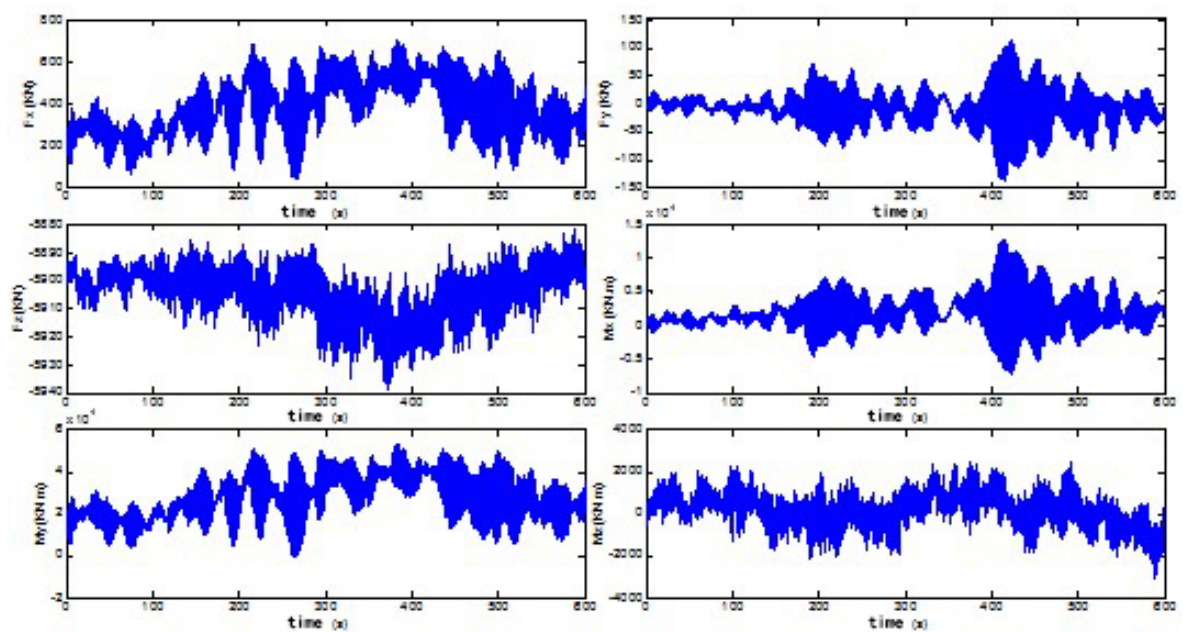

(a) $\mathrm{V}=6 \mathrm{~m} / \mathrm{s}$
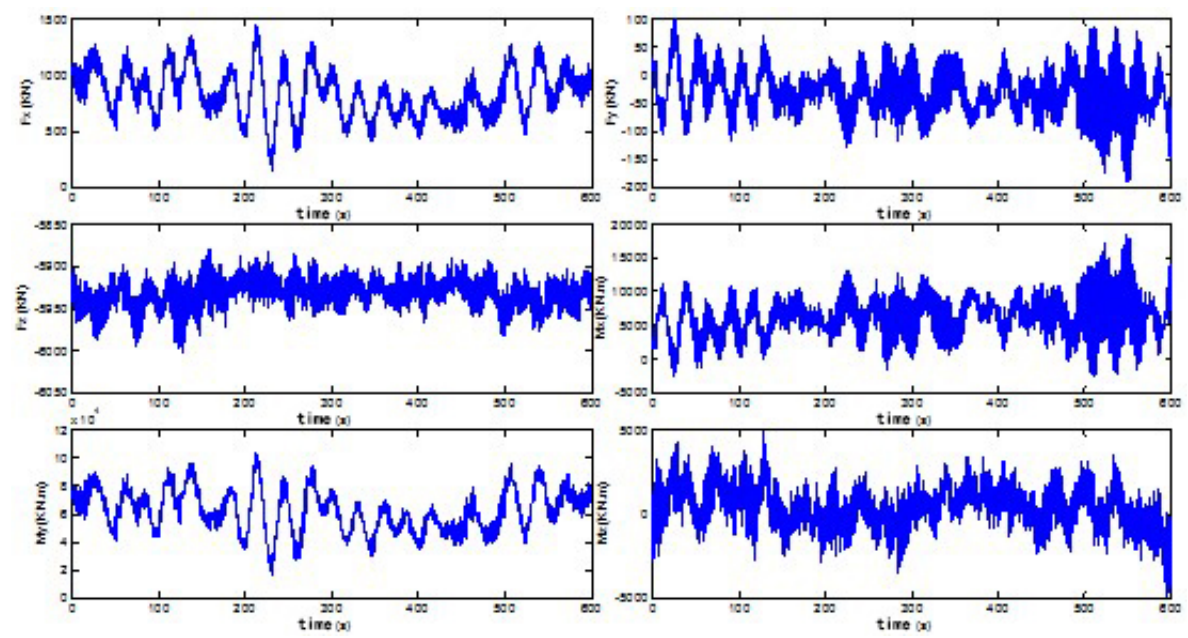

(b) $V=12 \mathrm{~m} / \mathrm{s}$ 

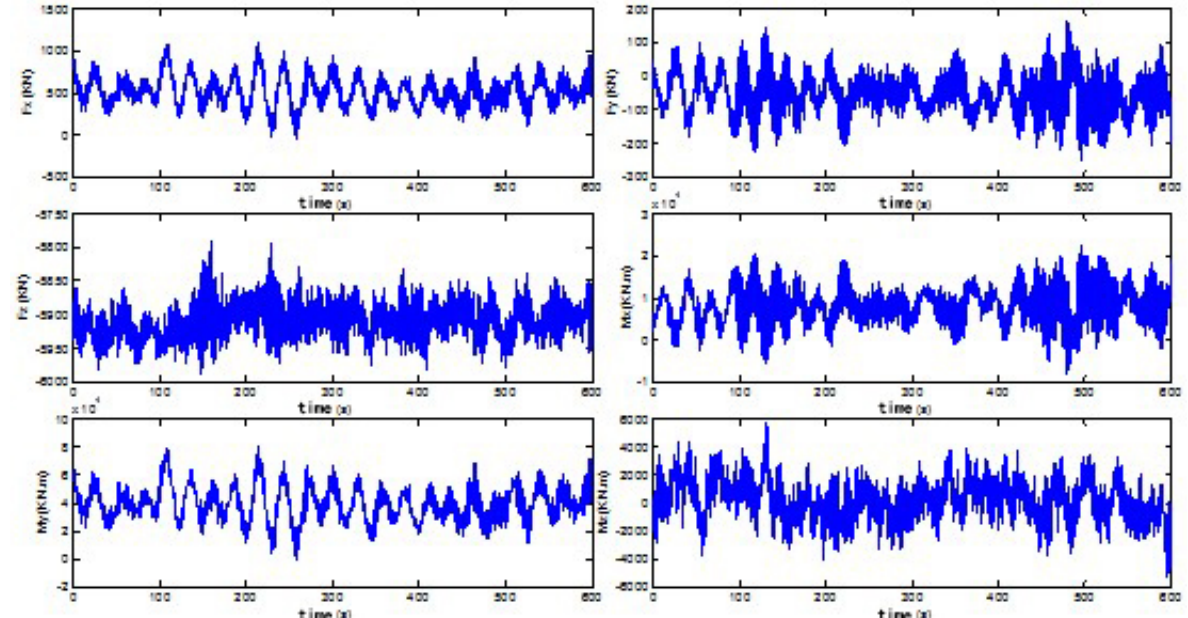

(c) $\mathrm{V}=18 \mathrm{~m} / \mathrm{s}$
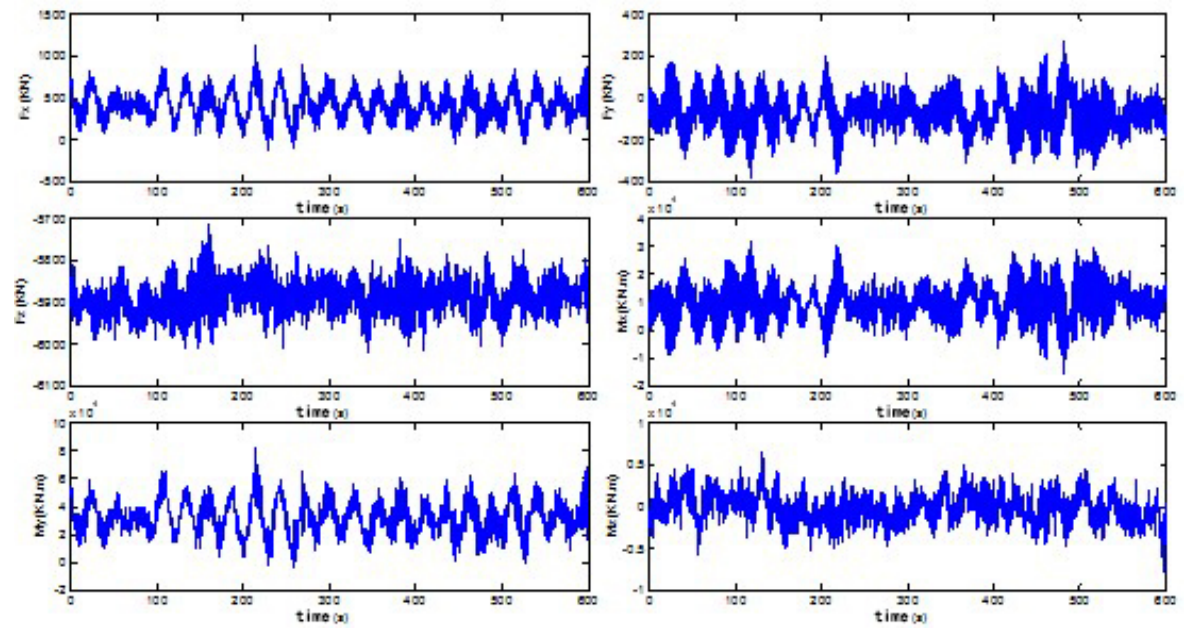

(d) $V=24 \mathrm{~m} / \mathrm{s}$

Fig. 5 Load of tower bottom fan

\subsection{Fatigue calculation steps and results under wind turbine load}

To prevent the resonance under the action of the wind turbine load,the inherent cycle of the wind power structure needs to avoid the wind turbine load excitation frequency.With the general structure of the stiffness is large, and the floating structure of the dynamic stress analysis involves the water elasticity, rigid body motion and elastic vibration, rigid and flexible components such as coupling, and the floating structure of the huge amount of grid, full time domain stress time calculation is very time consuming and difficult to apply. Therefore, under the action of the wind turbine load,the structural stress is calculated by the quasi-static method.which is the same as the structural stress calculation under the wave load. For the semi-submersible wind turbine, the movement cycle is generally long, dusk, roll, with pitch cycle more than 20s. But wind turbine load excitation frequency is generally $2 \sim 5$ s, much smaller than the structural movement of the inherent cycle, avoiding the structure Resonance. In this paper, the time series load calculated by FAST is loaded into the structure.The stress time series of the corresponding hotspots is obtained. The total fatigue damage is obtained by the rain flow counting method and the linear cumulative damage theory [9]. The critical load point fatigue calculation process is shown in Fig. 6.

Specific steps are as follows:

1) Six free degrees of unit load were applied to the bottom of the overall model wind turbine

LoadCase1 $=(1000 \mathrm{~N}, 0 \mathrm{~N}, 0 \mathrm{~N}, 0 \mathrm{Nm}, 0 \mathrm{Nm}, 0 \mathrm{Nm})$;

LoadCase2 $=(0 \mathrm{~N}, 1000 \mathrm{~N}, 0 \mathrm{~N}, 0 \mathrm{Nm}, 0 \mathrm{Nm}, 0 \mathrm{Nm})$;

LoadCase3 $=(0 \mathrm{~N}, 0 \mathrm{~N}, 1000 \mathrm{~N}, 0 \mathrm{Nm}, 0 \mathrm{Nm}, 0 \mathrm{Nm})$;

LoadCase4 $=(0 \mathrm{~N}, 0 \mathrm{~N}, 0 \mathrm{~N}, 1000 \mathrm{Nm}, 0 \mathrm{Nm}, 0 \mathrm{Nm})$;

LoadCase5 $=(0 \mathrm{~N}, 0 \mathrm{~N}, 0 \mathrm{~N}, 0 \mathrm{Nm}, 1000 \mathrm{Nm}, 0 \mathrm{Nm})$;

LoadCase6 $=(0 \mathrm{~N}, 0 \mathrm{~N}, 0 \mathrm{~N}, 0 \mathrm{Nm}, 0 \mathrm{Nm}, 1000 \mathrm{Nm})$.

Output the whole finite element model. Use Sestra for strength analysis; 
2) Through the Submod module, the boundary condition of the whole model is passed to the local model.Use Seatra to calculate the local structural stress response, marking the hotspot unit in the Xtract result file, and outputting hotspots to the three stress component under six degrees of freedom. Use the influence factor to illustrate the hot spot under the unit load. Fig.7 shows the equivalent stress influence coefficient under the action of LoadCase1 LoadCase6.

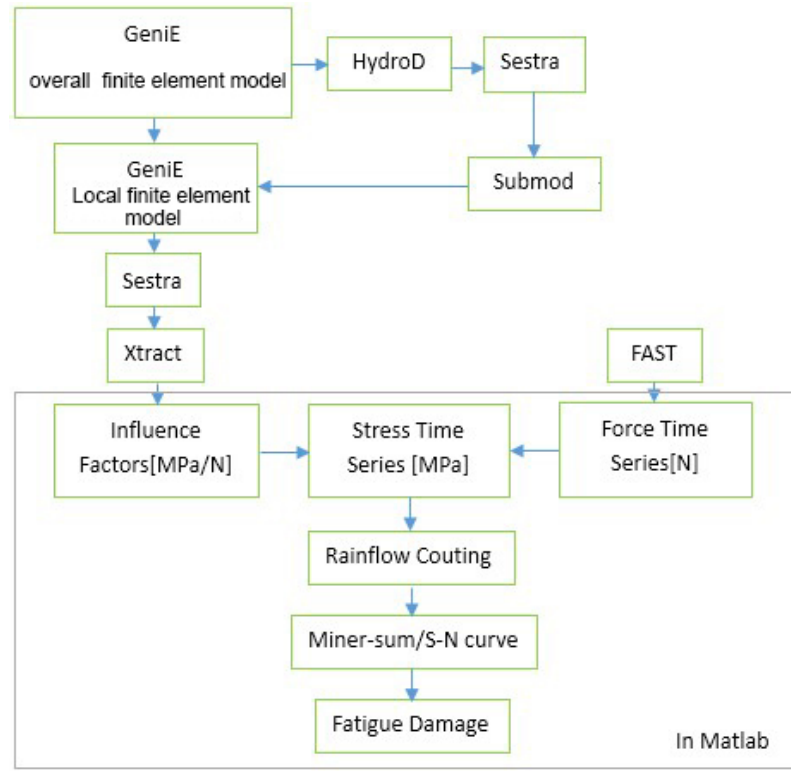

Fig.6 Flow chart of fatigue calculation under wind turbine load
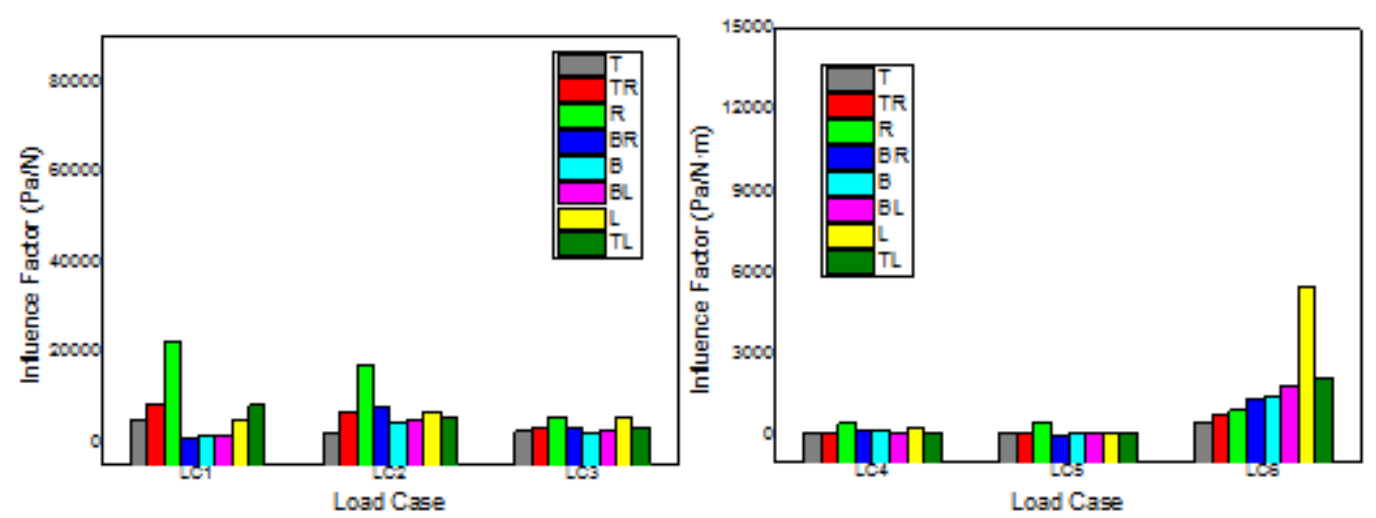

(a) damage coefficient of hot stress of No. 1 fatigue

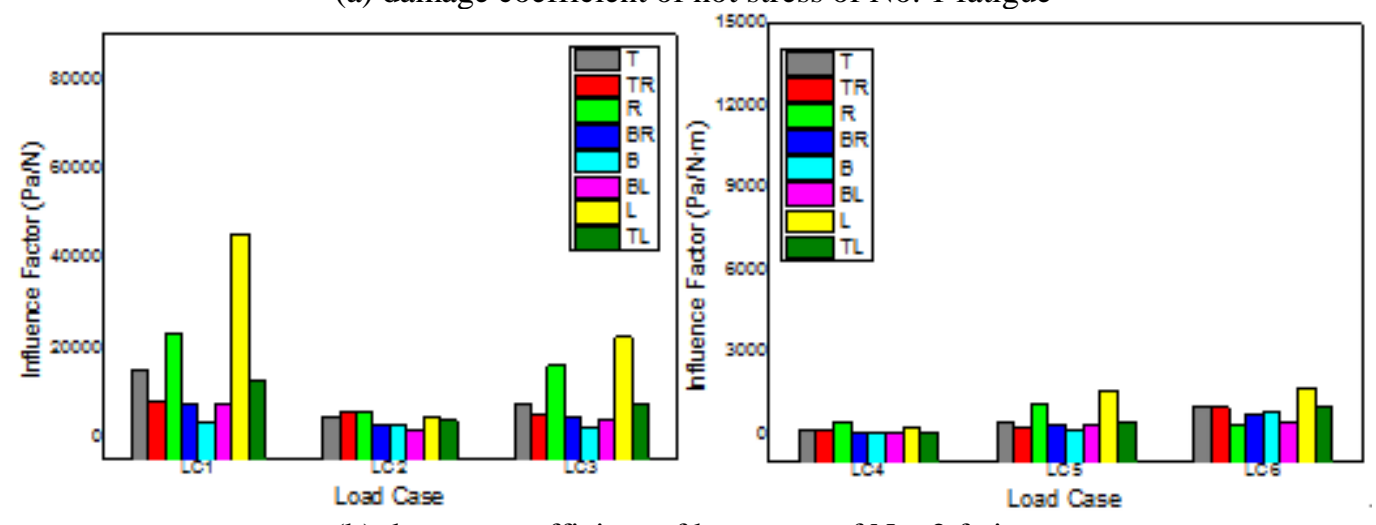

(b) damage coefficient of hot stress of No. 2 fatigue 

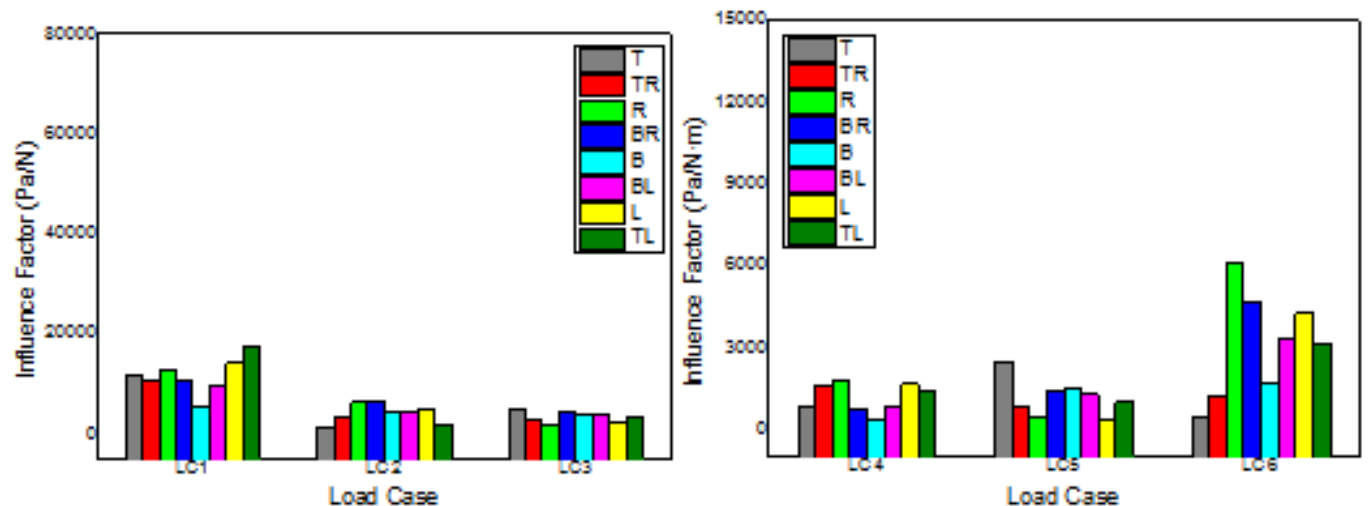

(c) damage coefficient of hot stress of No. 3 fatigue
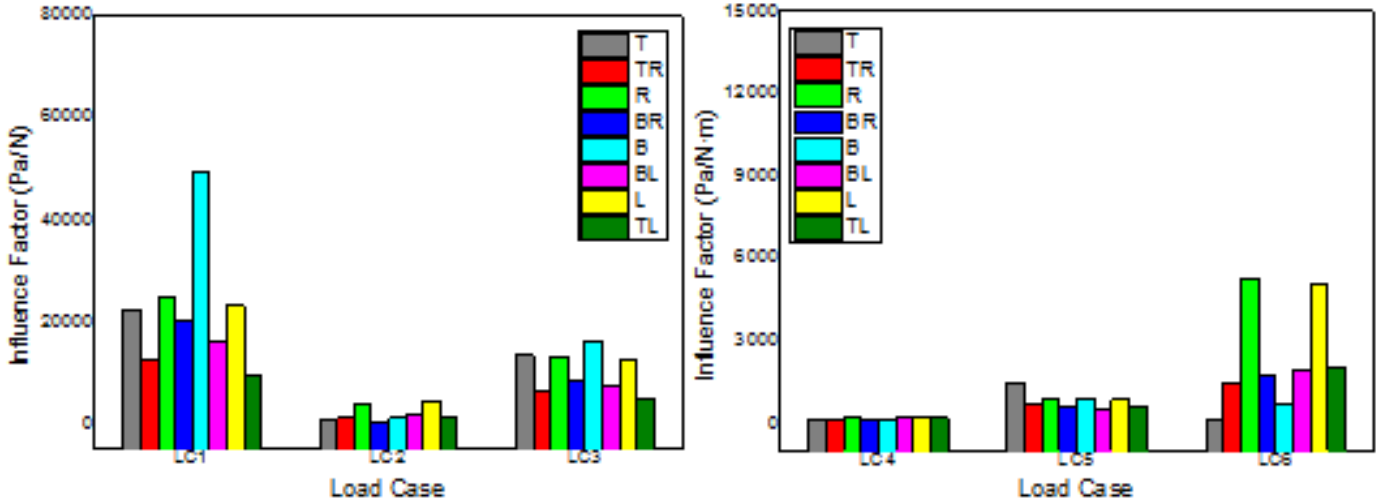

(d) damage coefficient of hot stress of No. 4 fatigue
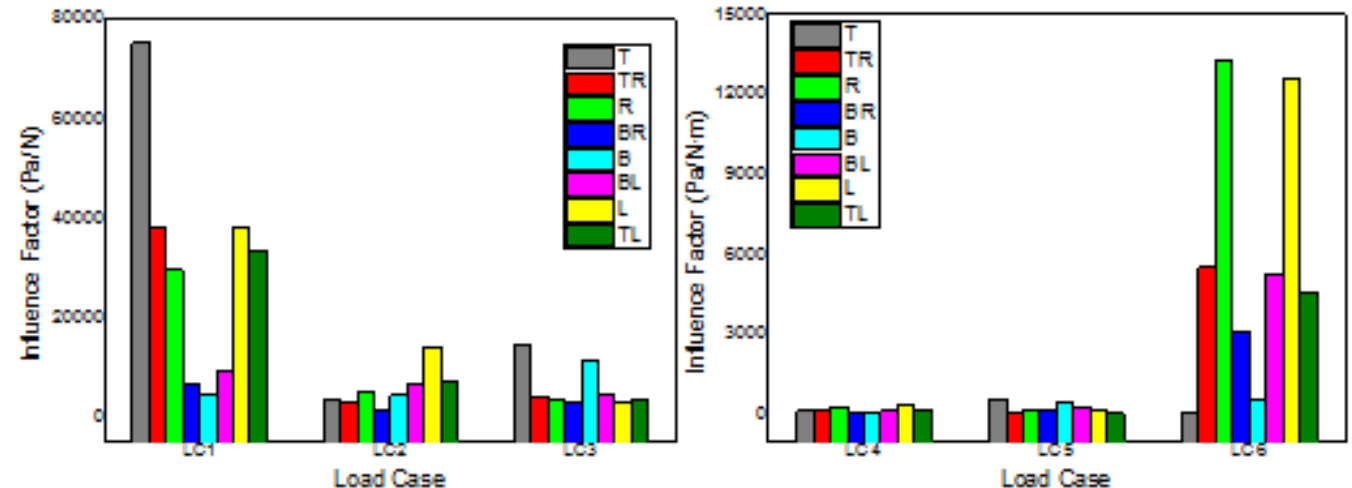

(e) damage coefficient of hot stress of No. 5 fatigue
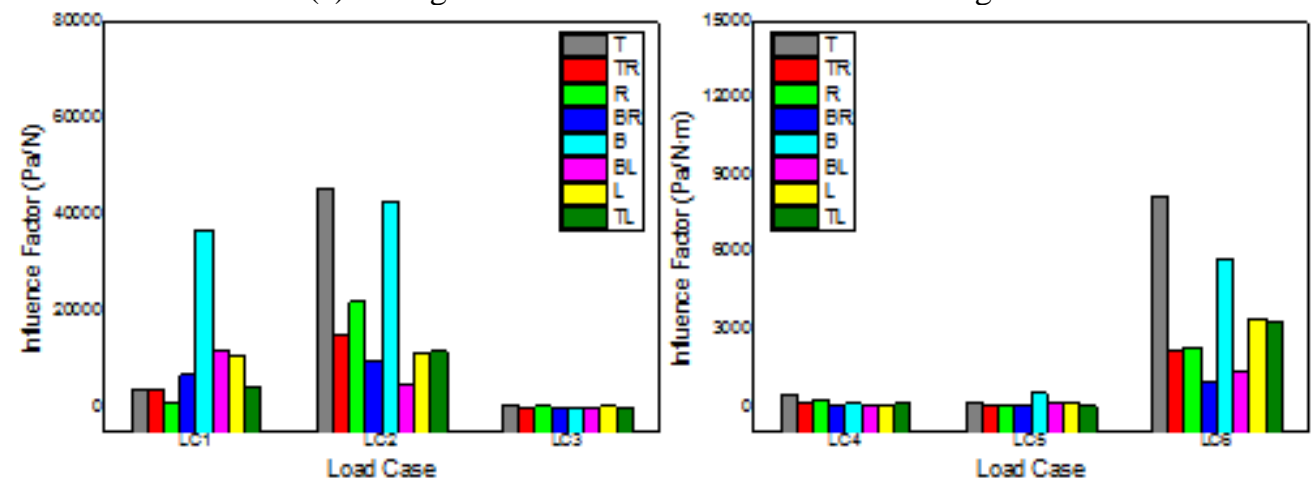

(f) damage coefficient of hot stress of No. 6 fatigue

Fig. 7 Hot spot stress coefficient of hot spot

The FAST output of the load time series, each group of loads and the stress components obtained here can be combined to get under the load of each group under the three stress components (for shell elements, only three stress components $\sigma_{x}, \sigma_{y}, \tau_{x y}$, for linear systems, Six degrees of freedom caused by the unit of the three stress 
components are linear superposition). The three stress components at each hot spot position are calculated by the following equation;

$$
\begin{aligned}
& \sigma_{x_{\text {total }}}^{t}=\sum_{i=1}^{6} \sigma_{x i} * F_{i}^{t} \\
& \sigma_{y_{\text {total }}}^{t}=\sum_{i=1}^{6} \sigma_{y i} * F_{i}^{t} \\
& \tau_{x y_{\text {total }}}^{t}=\sum_{i=1}^{6} \tau_{x y i} * F_{i}^{t}
\end{aligned}
$$

Among them, $\sigma_{x i}, \sigma_{y i}, \tau_{x y i}$ are the stress component of the hot spot under six unit loads. $F_{i}{ }^{t}$ is the load time series of six degrees of freedom at the bottom of the tower of FAST output, and the superscript $t$ represents the time point. The fatigue load on the offshore wind turbine infrastructure is a random load, and most of it is in the high cycle fatigue zone. It is proved that the Vonmises criterion can effectively predict the high-cycle fatigue damage by a large number of fatigue tests. Therefore, the Vonmises criterion is used to calculate the Vonmises criterion by the combination of the three stress components when the fatigue damage under the fan load is calculated:

$$
\sigma_{\text {vonMises }}=\sqrt{\sigma_{x}^{2}+\sigma_{y}^{2}-\sigma_{x} \sigma_{y}+3 \tau_{x y}^{2}}
$$

Under FAST calculation conditions, each case simulation to 600s load time series.Each direction has 11 wind speed.A total of 24 directions and 264 wind turbine load calculation conditions. For each fatigue calculation point, 264 equivalent stress time histories corresponding to 264 computational conditions are obtained. As shown in Fig. 8 is 0-degree direction $12 \mathrm{~m} / \mathrm{s}$ wind turbine load time force under the role of position 3 (pontoon upper pole connection) BR hot spot stress time curve.

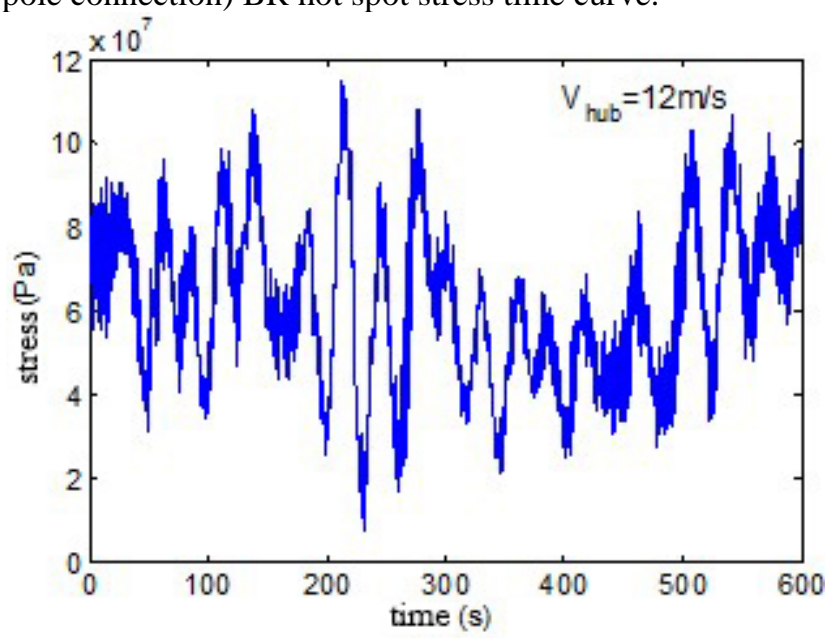

Fig. 8 No. 3 position BR hot spot stress time curve

For each fatigue calculation point, the paper counts the 264 stress time course rain flow.The resulting stress amplitude and the corresponding number of cycles are substituted into the selected SN curve to calculate the damage caused by the individual action under each condition. After which, according to the wind speed wind direction distribution probability table, the paper uses the linear cumulative damage theory.The damage under each working condition is multiplied by the corresponding occurrence probability.The total fatigue damage is obtained as shown in Table 2.

Table 2 Wind load under the structure of the key point of damage (after considering DFF)

\begin{tabular}{|c|c|c|c|c|c|c|c|c|}
\hline Location & $\mathrm{T}$ & $\mathrm{TR}$ & $\mathrm{R}$ & $\mathrm{BR}$ & $\mathrm{B}$ & $\mathrm{BL}$ & $\mathrm{L}$ & $\mathrm{TL}$ \\
\hline 1 & 0.001 & 0.001 & 0.117 & 0.001 & 0.001 & 0.001 & 0.013 & 0.001 \\
\hline 2 & 0.004 & 0.001 & 0.203 & 0.001 & 0.001 & 0.001 & 0.467 & 0.005 \\
\hline 3 & 0.412 & 0.287 & 0.406 & 0.134 & 0.265 & 0.353 & 0.333 & 0.309 \\
\hline 4 & 0.417 & 0.010 & 0.169 & 0.021 & 0.407 & 0.012 & 0.146 & 0.004 \\
\hline 5 & 0.373 & 0.011 & 0.428 & 0.001 & 0.001 & 0.010 & 0.006 & 0.005 \\
\hline 6 & 0.366 & 0.002 & 0.003 & 0.001 & 0.132 & 0.001 & 0.001 & 0.001 \\
\hline 7 & \multicolumn{8}{|c|}{0.002} \\
\hline
\end{tabular}




\section{Conclusions}

From the damage results, it can be seen that the fatigue damage caused by the wind turbine load mainly occurs at the horizontal connection of the upper part of the middle buoy and the brace connection at the lower part of the middle buoy. For the fatigue damage of Position 1, it can be seen from the thermal stress coefficient of the hot spots that the stress of the eight hot spots under Fz, Mx and My is not much different, but the stress under the action of the hot $\mathrm{R}$ is greater than that of the other points. The stress under the $\mathrm{L}$ is also greater than the other points.This indicates that the fatigue damage at $\mathrm{R}$ and $\mathrm{L}$ points is greater than the other six points. which is consistent with the actual damage obtained. For the Position 3 fatigue damage location (the middle buoy of the middle buoy) and Position 4 (middle buoy). The stress on the 4 th position of LoadCase 1 and LoadCase6 is greater than the stress of position 3, but the stress of position 4 is less than the stress of position 3 under the action of LoadCase4 and LoadCase5. According to the results of the damage degree, it can be seen that the hot spot fatigue damage on the 4th position is smaller than that of the 3rd position. It is shown that the influence of bending moment on fatigue damage is greater than that of transverse force and torque in six degrees of freedom component of wind turbine load.In each of the eight hot spots of each fatigue location, the maximum load values of the six Load Cases occur essentially at the crown or saddle point, and same Situation occurs for thermal damage. Which indicates that the stress concentration in the crown and saddle is greater than the others at $45^{\circ}$ position.

\section{Acknowledgements}

This article is financial supported by: Natural Science Foundation of Shandong Province (ZR2016EEM04); Shandong Province Key R \& D Special (2017GHY15101); Qingdao Industrial Training Program (17-6-3-26-gx); A Project of Shandong Province Higher Educational Science and Technology Program (J17KB018).

\section{References}

[1] Rakesh K, Saigal and Dan Dolan. MMI Engineering. Comparison of Design Guidelines for Offshore Wind Energy Systems[C]. Offshore Technology Conference(OTC),2007,18984:1-8.

[2] S. Butterfield, W. Musial, and J. Jonkman, et al. Engineering Challenges for Floating Offshore Wind Turbines[C]. NREL/CP-500-38776, September 2007.

[3] IEC 61400 - 3, Wind Turbines - Part 3: Design Requirements for Offshore Wind Turbines, International Electrotechnical Commission(IEC), 2006.

[4] Germanischer Lloyd Rules and Guidelines, IV - Industrial Services, Part 1 - Guideline for the Certification of Offshore Wind Turbines, 2005.

[5] J.M. Jonkman, M.L. Buhl, Jr. Loads Analysis of a Floating Offshore Wind Turbine Using Fully Coupled Simulation[C]. WindPower 2007 Conference \& Exhibition. Los Angeles, California, June 3-6, 2007.

[6] P. Schaumann, S. Lochte-Holtgreven, S. Steppeler. Special fatigue aspects in support structures of offshore wind turbines [J]. Mat.-wiss. u.Werkstofftech. 2011, 42(12): 1075-1081.

[7] Sergio Márquez-Domínguez, John D. S rensen. Fatigue Reliability and Calibration of Fatigue Design Factors for Offshore Wind Turbines [J]. Energies. 2012, 5: 1816-1834.

[8] Johannessen, K., Meling, T. S., and Haver, S.(2001).Joint Distribution for Wind and Waves in the Northern North Sea. ISOPE

[9] Kvittem M I, Moan T. Time domain analysis procedures for fatigue assessment of a semi-submersible win turbine[J]. Marine Structures, 2015, 40: 38-59. 